Supporting Information

\title{
Facile fabrication of small-sized palladium nanoparticles in nanoconfined spaces for low-temperature CO oxidation
}

Li-Ying Shi ${ }^{a, b}, Y u$-Xia Li ${ }^{a}$, Ding-Ming Xue ${ }^{a}$, Ming-Qi Shao , Meng-Xuan Gu ${ }^{a}$, Xiao-Qin Liu*a, Lin-Bing Sun *a

a State Key Laboratory of Materials-Oriented Chemical Engineering, Jiangsu National Synergetic Innovation Center for Advanced Materials (SICAM), College of Chemical Engineering, Nanjing Tech University, 30 South Puzhu Road, Nanjing 211816, China.

${ }^{\mathrm{b}}$ School of Pharmacy, Nanjing Medical University, Nanjing 210029, China 


\section{Experimental section}

\subsection{Chemicals}

Pluronic P123 was purchased from Aldrich. Tetraethylorthosilicate (TEOS) was purchased from Sinopharm. Hydrochloric acid $(\mathrm{HCl})$ were purchased from Shanghai Ling Feng. Palladium nitrate $\left[\mathrm{Pd}\left(\mathrm{NO}_{3}\right)_{2} \cdot 2 \mathrm{H}_{2} \mathrm{O}\right]$ was purchased from Macklin. $\mathrm{CO}$ gas was obtained from Nanjing Shangyuan Industrial Gas.

\subsection{Materials synthesis}

Preparation of SBA-15 follows a route described in literature ${ }^{1}$. Firstly, $3 \mathrm{~g}$ of Pluronic $\mathrm{P} 123$ was added into mixture of $90 \mathrm{~g}$ of $2 \mathrm{~mol} \cdot \mathrm{L}^{-1} \mathrm{HCl}$ solution and $22.5 \mathrm{~g}$ of water, and kept stirring until it was clear. Then the mixture was maintained stirring at $40{ }^{\circ} \mathrm{C}$ for $24 \mathrm{~h}$ after 4.25 $\mathrm{g}$ of tetraethylorthosilicate (TEOS) was poured. Lastly, aging process was performed at $100{ }^{\circ} \mathrm{C}$ for $24 \mathrm{~h}$. The as-made SBA-15 (marked as AS) containing templates was obtained after filtration. The as-made SBA-15 with small pore size of $5.4 \mathrm{~nm}$ was obtained by decreasing the preparation temperature to $35^{\circ} \mathrm{C}$ and aging temperature to $80^{\circ} \mathrm{C}$, which is denoted $\mathbf{A S}(\mathbf{S})$. AS was subjected to calcination under flowing air at $550{ }^{\circ} \mathrm{C}$ for $5 \mathrm{~h}$, and the resulting material without the template P123 was denoted as CS.

The precursor of $\mathrm{Pd}\left(\mathrm{NO}_{3}\right)_{2} \cdot 2 \mathrm{H}_{2} \mathrm{O}$ was ground into $\mathbf{A S}$ under ambient conditions for $0.5 \mathrm{~h}$. The mixed power was then treated by calcination at $300{ }^{\circ} \mathrm{C}$ for $3 \mathrm{~h}$ in flowing air, and reduced at $200{ }^{\circ} \mathrm{C}$ for $2 \mathrm{~h}$ under $10 \% \mathrm{H}_{2} / \mathrm{Ar}$ atmosphere. The resultant materials were marked as $n \mathrm{Pd}$ AS (where $n=1,2$, or 5 and means the weight percent of Pd per gram of the resultant samples). The counterparts $n \mathrm{Pd}-\mathbf{C S}$ samples were prepared by using $\mathbf{C S}$ as supports in the same process.

\subsection{Characterization}

X-ray diffraction (XRD) patterns of samples were obtained using a Bruker D8 Advance diffractometer equipped with $\mathrm{Cu} \mathrm{K \alpha}$ radiation at $40 \mathrm{kV}$ and $40 \mathrm{~mA}$ (Bruker, GER). Transmission electron microscopy (TEM) was taken using a JEM-2010UHR electron 
microscope performed at the operation voltage of $200 \mathrm{kV}$ (Nippon electronics co. LTD, JPN). Spherical aberration electron microscope was operated at the voltage of $200 \mathrm{kV}$ (Titan cubed themis G2300, USA). The $\mathrm{N}_{2}$ adsorption-desorption isotherms were collected by ASAP2020 apparatus (Micromeritics, USA) at $77 \mathrm{~K}$. Before analysis materials were treated by vacuum at $150{ }^{\circ} \mathrm{C}$ for $3 \mathrm{~h}$. Fourier transform infrared (IR) measurements were recorded on a Nicolet Nexus 470 spectrometer (Thermo, USA). TG analysis was conducted from room temperature to $800{ }^{\circ} \mathrm{C}$ with a thermobalance (STA-499C, Netzsch, GER) in flowing air. The X-ray photoelectron spectroscopy (XPS) analysis (VG Scientific Ltd, UK) was operated on a Physical Electronic PHI-550 spectrometer which was equipped with an Al K $\alpha$ X-ray source (hv=1486.6 $\mathrm{eV}$ ) and was carried out at $35 \mathrm{~mA}$ of anode current and $10 \mathrm{kV}$ of potential acceleration.

\subsection{Catalytic tests}

The $\mathrm{CO}$ oxidation was performed using a quartz tube (inner diameter $4 \mathrm{~mm}$, outer diameter $6 \mathrm{~mm}$ ) filled with $30 \mathrm{mg}$ of catalysts (20-40 mesh) in a fixed bed reactor. The catalysts were pretreated in $10 \% \mathrm{H}_{2} / \mathrm{Ar}$ airflow at $200{ }^{\circ} \mathrm{C}$ for $2 \mathrm{~h}$, then cooled down and shifted to a mixture of $\mathrm{CO}, \mathrm{O}_{2}$ and $\mathrm{Ar}\left(1 \mathrm{vol} \% \mathrm{CO}, 10 \mathrm{vol} \% \mathrm{O}_{2}, 89 \mathrm{vol} \% \mathrm{Ar}, 15 \mathrm{~mL} / \mathrm{min}\right.$ per reactor). The catalytic tests were conducted from 35 to $300{ }^{\circ} \mathrm{C}$ with $2{ }^{\circ} \mathrm{C} / \mathrm{min}$ heating rate. The reaction products were analyzed by online Hiden Analytical mass spectrum (Hiden, UK). The CO conversions $\left(X_{\mathrm{CO}}\right)$ were calculated as follows: $X_{\mathrm{CO}}=\left([\mathrm{CO}]_{\text {in }}-[\mathrm{CO}]_{\text {out }}\right) /[\mathrm{CO}]_{\text {in }} \times 100(\%)$. 


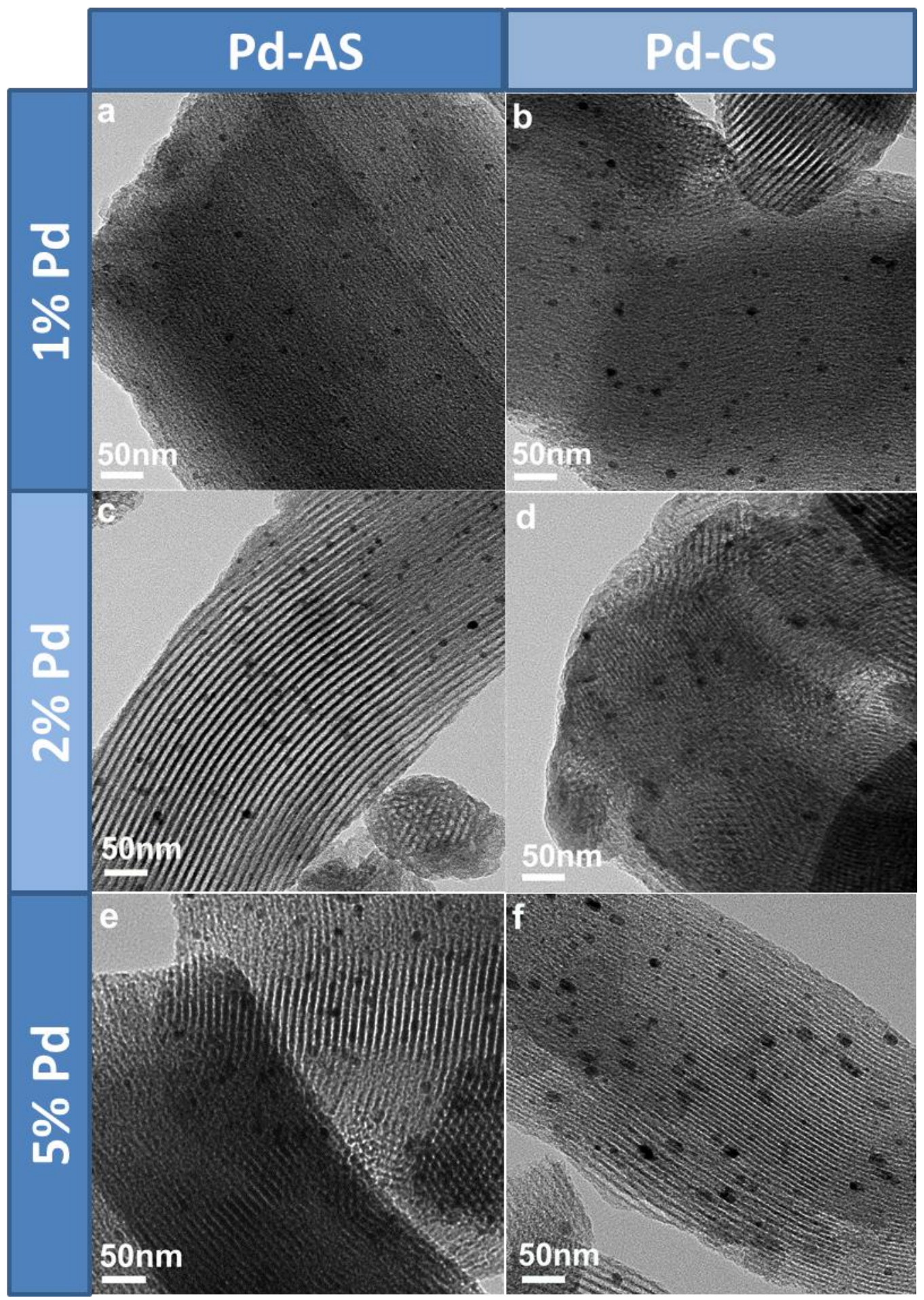

Fig. S1 Bright-field TEM images of the samples (a) 1Pd-AS, (b) 1Pd-CS, (c) 2Pd-AS, (d) 2PdCS, (e) 5Pd-AS and (f) 5Pd-CS. 

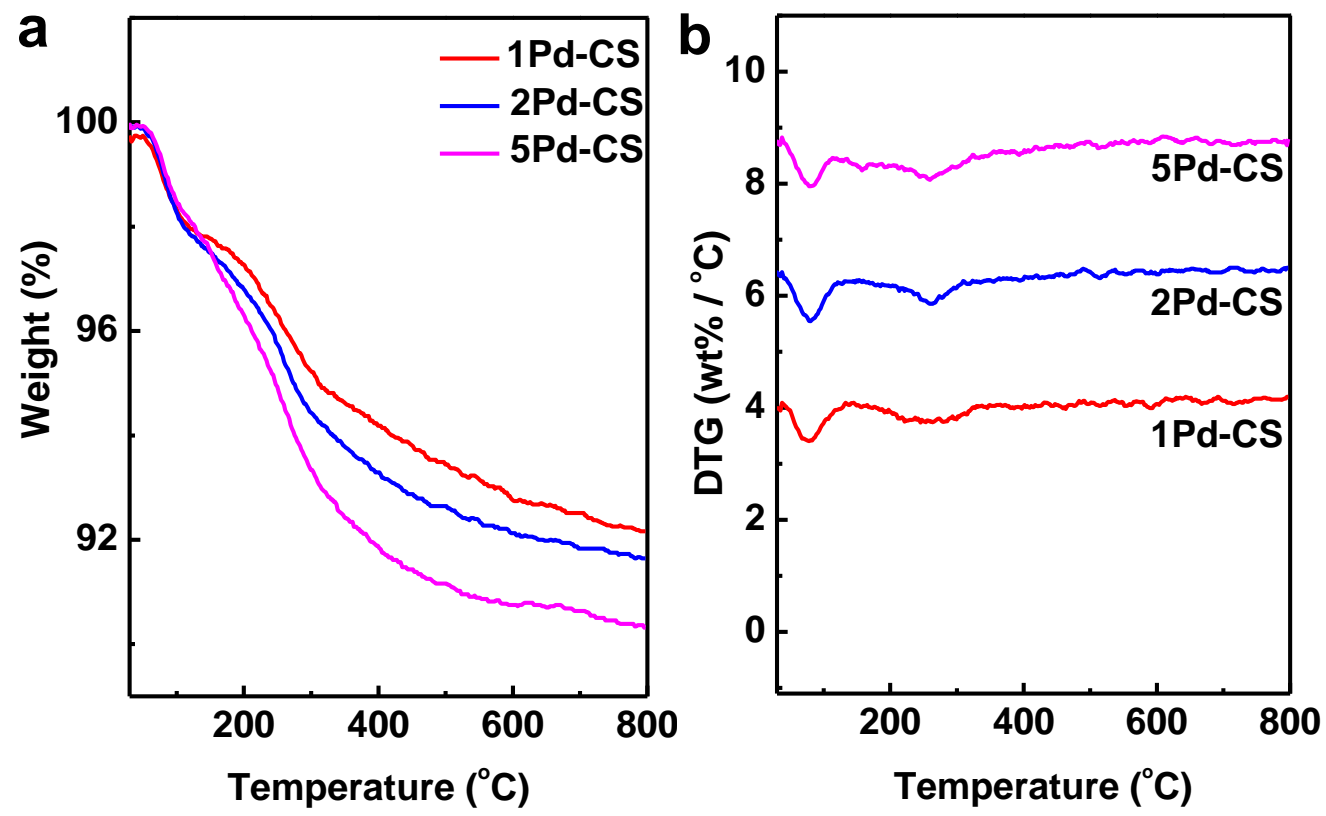

Fig. S2 (a) TG and (b) DTG curves of samples of Pd-CS before calcination. 

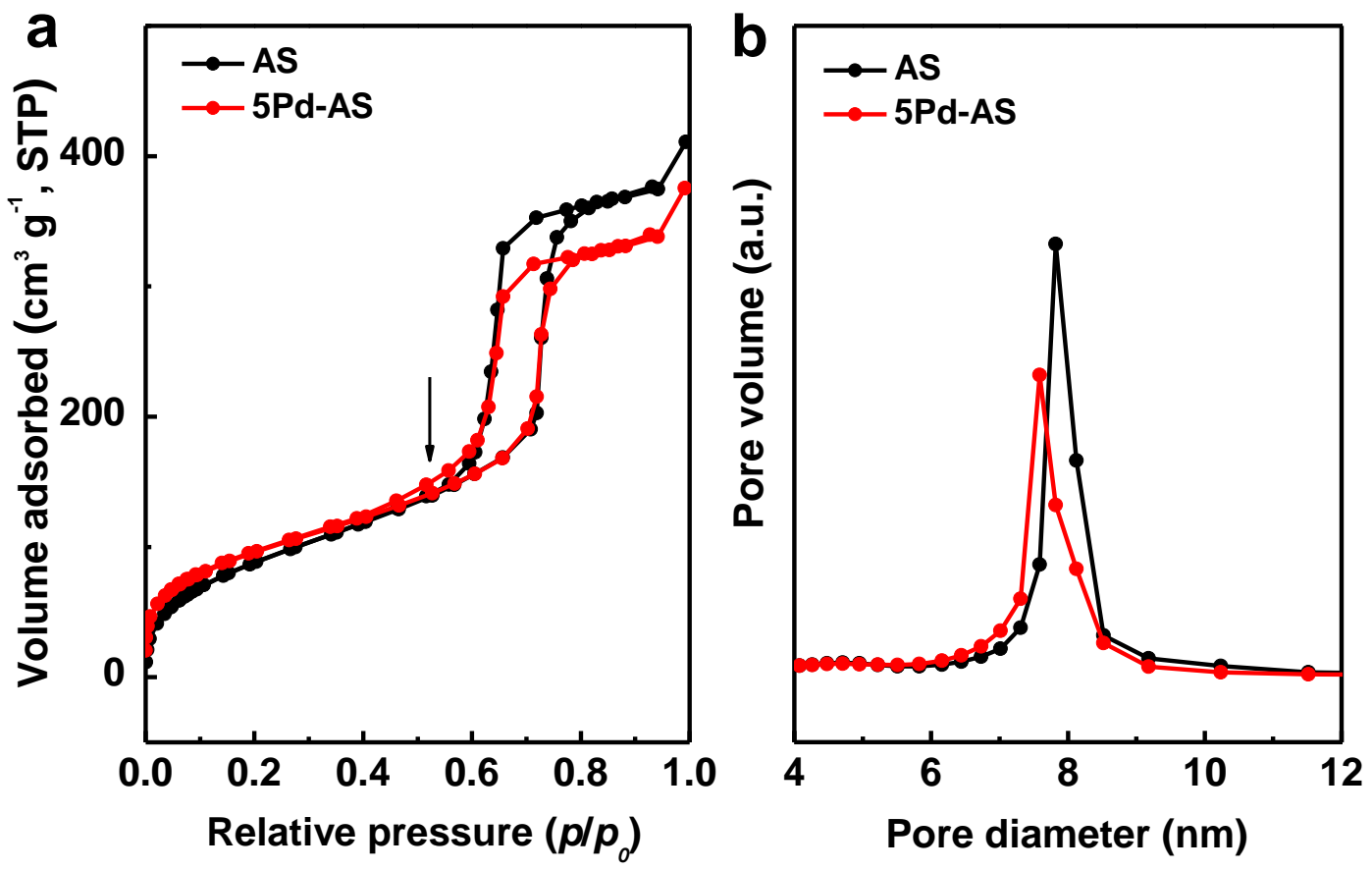

Fig. S3 (a) $\mathrm{N}_{2}$ adsorption-desorption isotherms and (b) pore size distributions of as-made SBA-15 before and after loading $\mathrm{Pd}\left(\mathrm{NO}_{3}\right)_{2}$. 

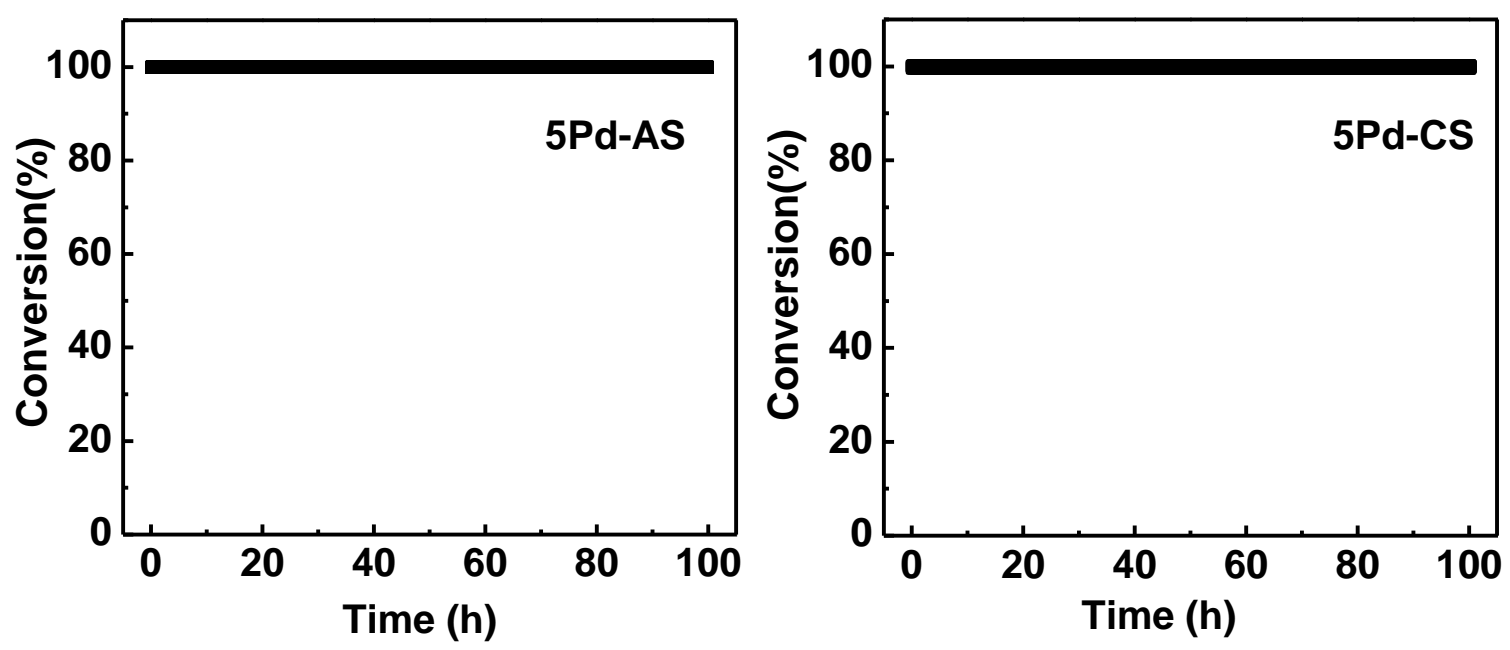

Fig. S4 Stability evaluation of the catalysts $5 \mathrm{Pd}-\mathbf{A S}$ and $5 \mathrm{Pd}-\mathbf{C S}$ at $140{ }^{\circ} \mathrm{C}$ for $\mathrm{CO}$ oxidation 


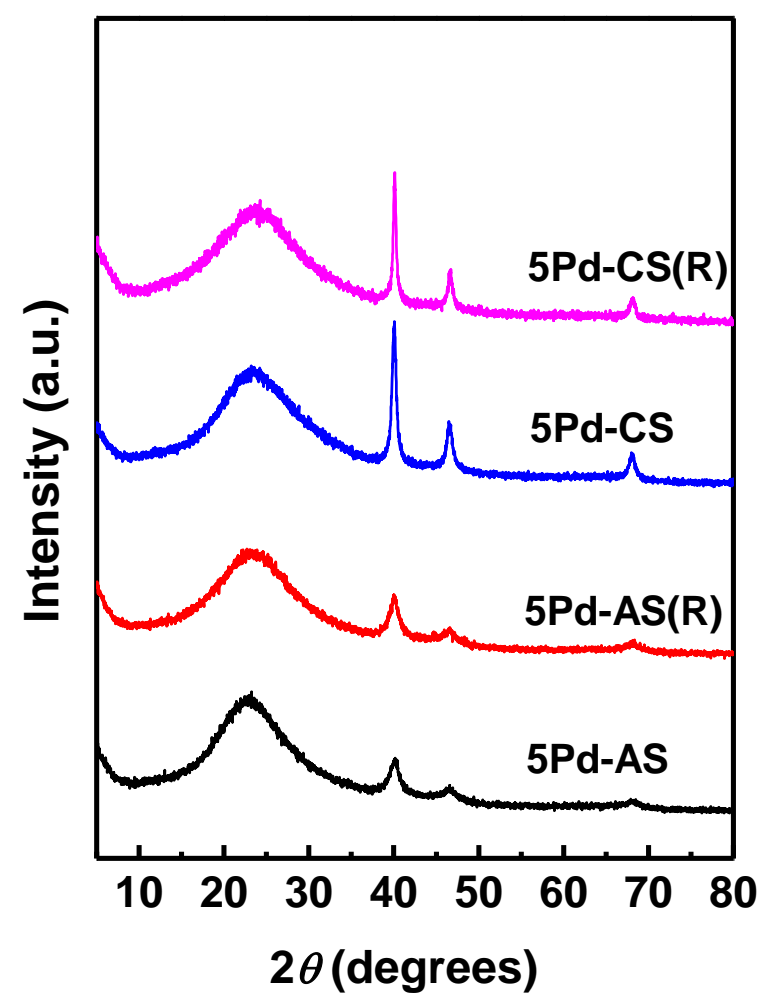

Fig. S5 Wide-angle XRD patterns of the fresh 5Pd-AS, 5Pd-CS and their recovered sample after reaction at $140{ }^{\circ} \mathrm{C}$ for $100 \mathrm{~h}$. 


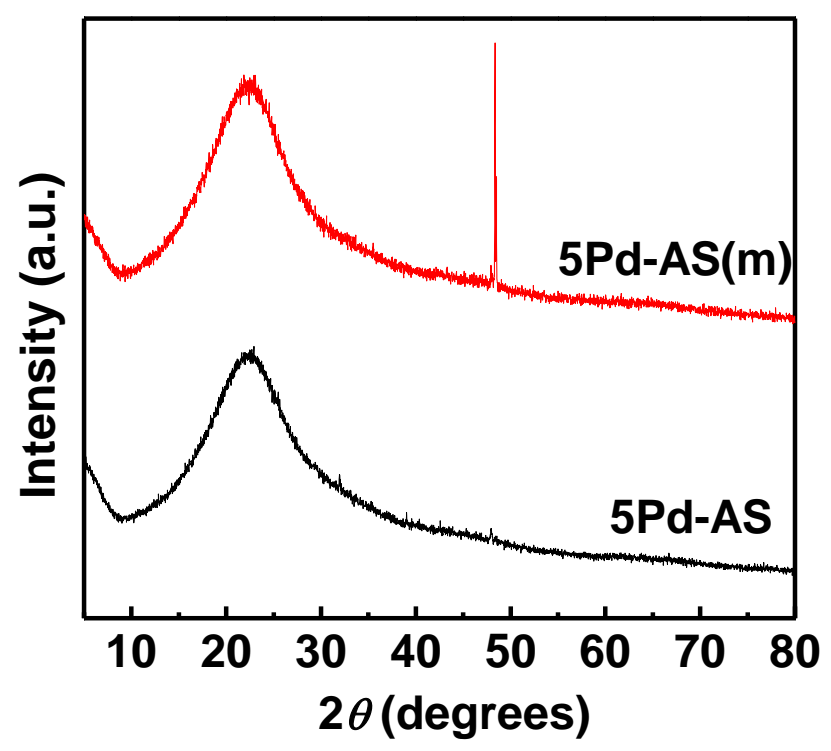

Fig. S6 Wide-angle XRD patterns of 5Pd-AS and 5Pd-AS(m) before calcination. 


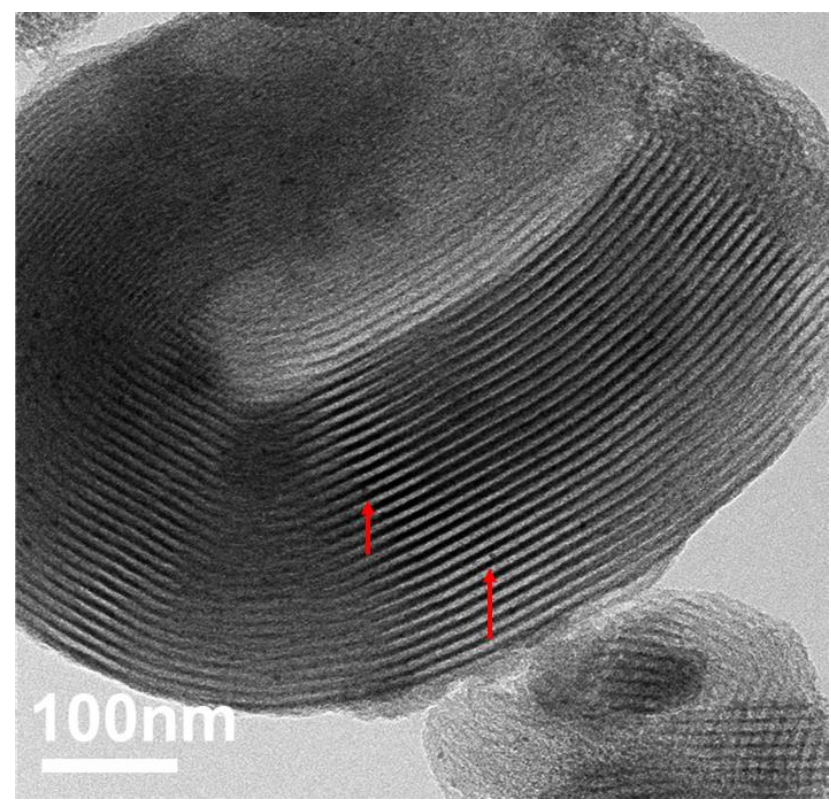

Fig. S7 TEM image of the sample of AS after introducing $\mathrm{Pd}\left(\mathrm{NO}_{3}\right)_{2}$. 


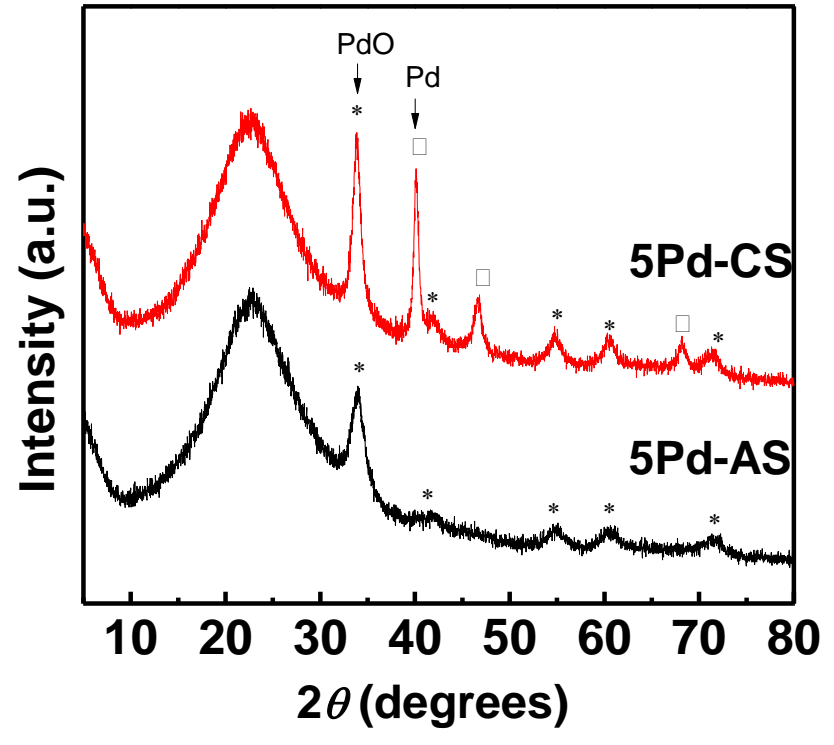

Fig. S8 Wide-angle XRD patterns of 5Pd-AS and 5Pd-CS after calcination in air. 


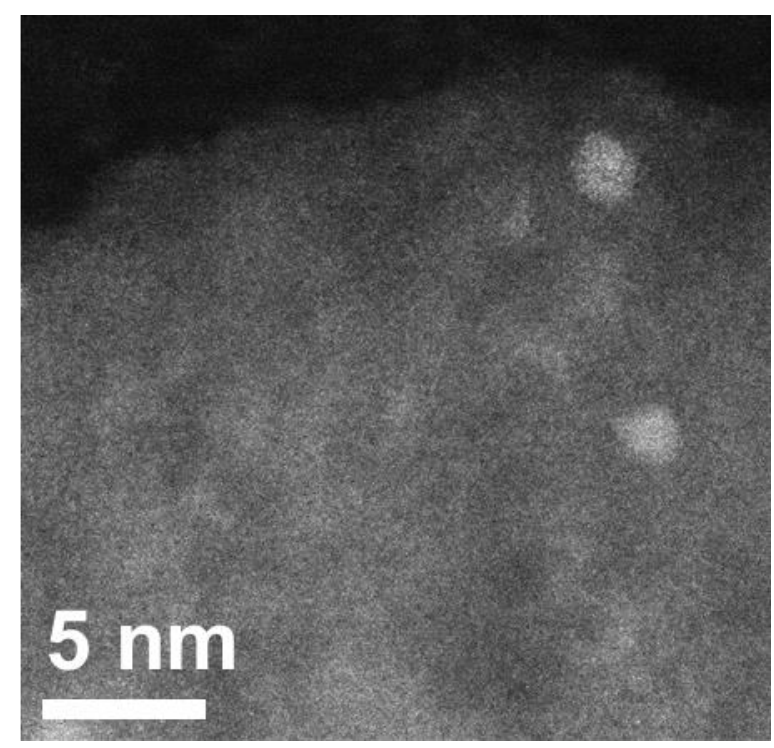

Fig. S9 SAEM image of the sample of 1Pd-AS. 


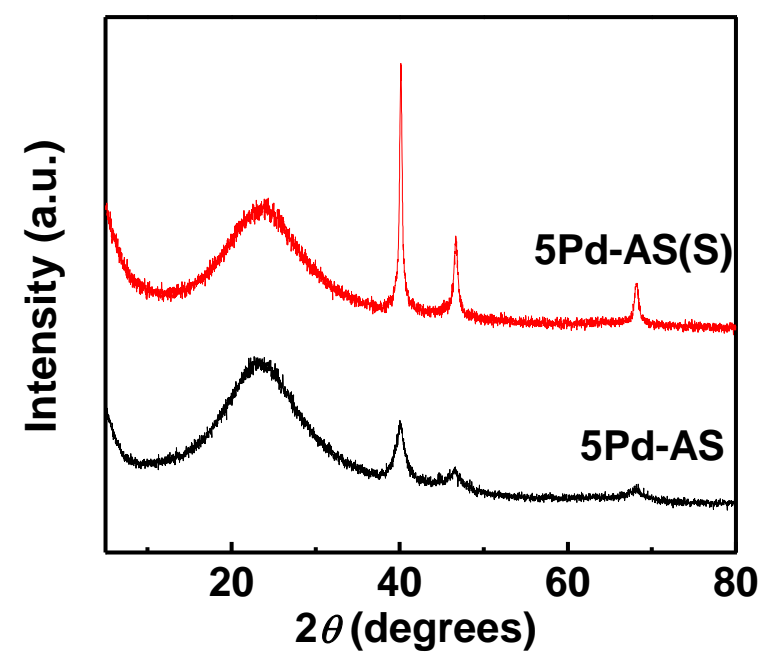

Fig. S10 Wide-angle XRD patterns of 5Pd-AS prepared from SBA-15 with large pore size (7.8 $\mathrm{nm})$ and 5Pd-AS(S) prepared from SBA-15 with small pore size $(5.4 \mathrm{~nm})$. 
Table S1 The catalytic performance of different samples

\begin{tabular}{cccc}
\hline Sample & $\mathrm{T}_{\mathrm{ig}}\left({ }^{\circ} \mathrm{C}\right)$ & $\mathrm{T}_{100}\left({ }^{\circ} \mathrm{C}\right)$ & Reference \\
\hline $5 \mathrm{PdAS}$ & 120 & 140 & This work \\
$10 \% \mathrm{Pd} / \mathrm{SiO}_{2}$ & 223 & 225 & 2 \\
$\mathrm{Pd} / \mathrm{COP}-4^{a}$ & 145 & 185 & 4 \\
$3 \% \mathrm{Pd} / \mathrm{NTP}^{b}$ & 110 & 160 & 5 \\
$0.5 \% \mathrm{Pd} / \mathrm{MgO}^{b}$ & $<100$ & 140 & 6 \\
$1 \% \mathrm{Pd} / \mathrm{Al}_{2} \mathrm{O}_{3}$ & 110 & 160 & 7 \\
$3 \% \mathrm{Pd} / \mathrm{CoMCM}-41$ & 100 & 130 & \\
\hline
\end{tabular}

${ }^{a} \mathrm{COP}$ : covalent organic polymer;

${ }^{b}$ NTP: triptycene-based microporous polymer. 


\section{References}

(1) Jiang, W. J.; Yin, Y.; Liu, X. Q.; Yin, X. Q.; Shi, Y. Q.; Sun, L. B. Fabrication of supported cuprous sites at low temperatures: an efficient, controllable strategy using vapor-induced reduction. J. Am. Chem. Soc. 2013, 135, 8137.

(2) Al Soubaihi, R. M.; Saoud, K. M.; Ye, F.; Myint, M. T. Z.; Saeed, S.; Dutta, J. Synthesis of hierarchically porous silica aerogel supported Palladium catalyst for low-temperature CO oxidation under ignition/extinction conditions. Micro. Meso. Mater. 2020, 292, 109758.

(3) Zhou, Y.; Xiang, Z. H.; Cao, D. P.; Liu, C. J. CovaChemical Communicationslent organic polymer supported palladium catalysts for CO oxidation. Chem. Commun. 2013, 49, 5633.

(4) Liang, Q.; Liu, J.; Wei, Y. C.; Zhao, Z.; MacLachlan, M. J. Palladium nanoparticles supported on a triptycene-based microporous polymer: highly active catalysts for CO oxidation. Chem. Commun. 2013, 49, 8928.

(5) Li, L. C.; Liu, X. J.; He, H.; Zhang, N. Q.; Liu, Z. W.; Zhang, G. Z. A novel two-dimensional $\mathrm{MgO}-\mathrm{h}-\mathrm{BN}$ nanomaterial supported Pd catalyst for $\mathrm{CO}$ oxidation reaction. Catal. Today 2019, 332, 214.

(6) Haneda, M.; Todo, M.; Nakamura, Y.; Hattori, M. Effect of Pd dispersion on the catalytic activity of $\mathrm{Pd} / \mathrm{Al}_{2} \mathrm{O}_{3}$ for $\mathrm{C}_{3} \mathrm{H}_{6}$ and $\mathrm{CO}$ oxidation. Catal. Today 2017, 281, 447.

(7) Hassan, H. M.; Betiha, M. A.; Elshaarawy, R. F.; El-Shall, M. S. Promotion effect of palladium on $\mathrm{Co}_{3} \mathrm{O}_{4}$ incorporated within mesoporous MCM-41 silica for CO Oxidation. Appl. Surf. Sci. 2017, 402, 99. 